\title{
PET-CT imaging in a patient with progressive supranuclear palsy
}

\section{Imagens de PET-CT em um paciente com paralisia supranuclear progressiva}

Anderson Benine Belezia', Victor Hugo Rocha Marussi', James Yared³, José Luiz Pedroso², Orlando G. Barsottini², Acary Souza Bulle Oliveira², Lázaro Luiz Faria do Amaral ${ }^{1}$

A 67-year-old woman presented with falls, cognitive impairment, mild upgaze palsy and parkinsonism for 3 years. A MRI was unremarkable. A PET-CT with fluorodeoxyglucose (FDG) disclosed reduced metabolism in thalami, midbrain and frontal cortex (Figure 1), suggesting progressive supranuclear palsy (PSP). Posterior MRI showed typical features observed in PSP (Figure 2).
PSP is a neurodegenerative disease which affects brainstem and basal ganglia ${ }^{1}$. Early differentiation between PSP and other atypical parkinsonism is a challenge ${ }^{1}$. MRI abnormalities in PSP usually appear in advanced stages ${ }^{2}$. In PSP, PET-CT involves upper brainstem, caudate nuclei, insula cortices and frontal cortex ${ }^{3,4}$. Functional imaging, such as PET-CT, may be relevant in early differentiation between Parkinson's disease and atypical parkinsonism ${ }^{4}$.
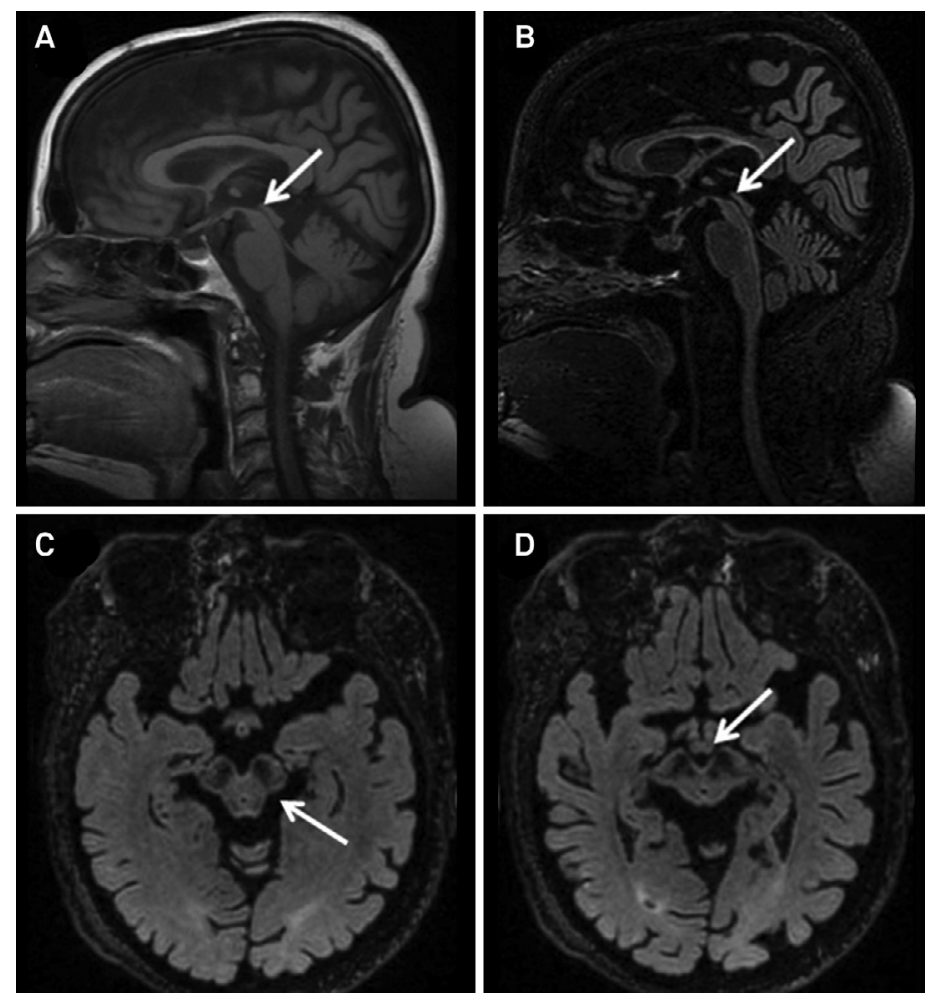

Figure 1. PET-CT imaging with fluorodeoxyglucose (FDG) of the patient described. Normal metabolism is red, and reduced metabolism is green. The image demonstrates reduced metabolism in medial frontal cortex and anterior portion of the cingulate gyrus (arrows A), and in upper midbrain (arrow B).

${ }^{1}$ Hospital Beneficência Portuguesa de São Paulo, Med Imagem, Sao Paulo SP, Brazil; Universidade Federal de São Paulo, Departamento de Neurologia, Sao Paulo SP, Brazil; 


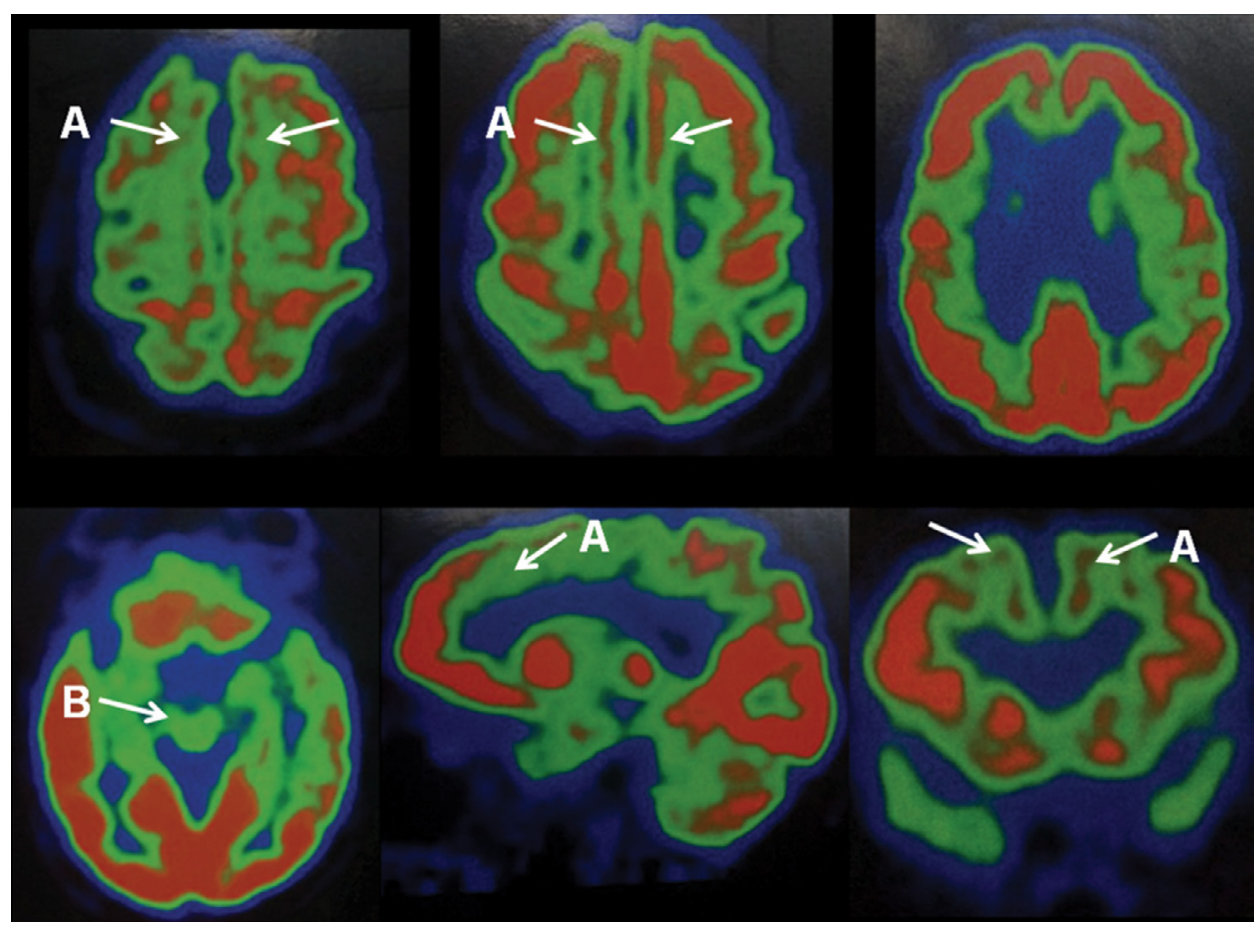

Figure 2. Sagittal T1 (A) and FLAIR-weighted (B) brain MRI show midbrain atrophy with antero-posterior midline diameter reduction and flattening of the superior midbrain ("Pinguin" sign) (arrows). Axial FLAIR sequences show concave lateral margin of the tegmentum ("morning glory" sign) (C) and enlarged interpeduncular cistern (D).

\section{References}

1. Barsottini OG, Felicio AC, Aquino CC, Pedroso JL. Progressive supranuclear palsy: new concepts. Arq Neuropsiquiatr. 2010;68(6):93846. http://dx.doi.org/10.1590/S0004-282X2010000600020

2. Barsottini OG, Ferraz HB, Maia Jr AC, Silva CJ, Rocha AJ. Differentiation of Parkinson's disease and progressive supranuclear palsy with magnetic resonance imaging: the first Brazilian experience. Parkinsonism Relat Disord. 2007;13(7):389-93. http://dx.doi.org/10.1016/j.parkreldis.2006.12.011
3. Tatsch K. Positron emission tomography in diagnosis and differential diagnosis of Parkinson`s disease. Neurodegener Dis. 2010;7(5):330-40. http://dx.doi.org/10.1159/000314499

4. Garraux G, Phillips C, Schrouff J, Kreisler A, Lemaire C, Dequeldre $\mathrm{C}$ et al. Multiclass classification of FDG PET scans for the distinction between Parkinson's disease and atypical parkinsonian syndromes. Neuroimage Clin. 2013;2:883-893. http://dx.doi.org/10.1016/j.nicl.2013.06.004

\section{ERRATUM}

In the article "PET-CT imaging in a patient with progressive supranuclear palsy" published in the journal Arquivos de Neuro-Psiquiatria, 2015;73(4), in the pages 364 and 365.

The Figure 2 was published in place of Figure 1.

The Figure 1 was publised in place of Figure 2. 